\title{
Insights into social responsibility in global health
}

\section{Background}

Over the last decade a renewed interest within the academic community in social responsibility and international cooperation has led to the creation of more than ninety public private partnerships in global health [1]. Many networking programmes have been established between high and low income countries to strengthen international links and promote capacity building. Medical research has become an important and critical vehicle of collaborative and cooperative programmes. The European and Developing Countries Trial Partnership (EDCTP) represents an excellent example of a multilateral initiative supporting the development of subSaharan countries through clinical research. In Austria, the Medical University of Vienna has also been engaged in Global Health programmes since its reorganization as an independent institution in 2004.

\section{Social responsibility in global health: why, who and how?}

What are the incentives for high income countries to be involved in international cooperation? Social responsibility is often the answer given. But what is social responsibility in global health? It could be a mixture of altruism towards poorer countries and of self interest for controlling the spread of many diseases that threaten also more developed areas in the world. In fact, to control the spread of HIV, tuberculosis, malaria, influenza and other infectious diseases can be considered as a moral duty but other would say that it is just investing in auto-protection since microbes do not recognize borders [2]. In other words, social responsibility can be seen as the result of the aggregation of different incentives: the altruism of the individuals and the interest of the institutions in controlling the global spread of diseases [3].

International cooperation in global health finds also its existing reasons in the need of breaking the loop of poverty and bad health. The relationship between poor health and poverty works in both directions: poor health leads to poverty and poverty does not allow creating the conditions for any health improvement $[4,5]$. Most of the low income countries are trapped in this loop and can not get out through their own forces; an external force (an exogenous shock, using an economic expression) is needed to break this perverse mecha-

Correspondence: Raquel González Álvarez, MD, MPH, E-mail: Raquel.gonzalez@cresib.cat; Elisa Sicuri, PhD,

E-mail: elisa.sicuri@cresib.at, Barcelona Centre for International Health Research (CRESIB), Hospital Clínic, Universitat de Barcelona, Rosselló 132, 4-2, 08036 Barcelona, Spain nism. International cooperation in global health can help breaking this loop by bringing resources and generating development opportunities in low income countries.

Next, who should be socially responsible for global health? Public institutions representing governments and international agencies have traditionally lead the initiatives. Again, the EDCTP is a living example of an international partnership created as a response to the global health crisis with public contribution of its member states [6]. Recently, the international community has witnessed an unprecedented effort from the private sector to join the fight against disease and also contribute to Global Health programmes [7, 8]. According to Beeharry [1], there are several incentives for the private foundations and companies to take part in these programmes: a) the creation of markets attractive enough to justify the research and development, b) the benefits for the brand image and the launch of new products and c) the potential impact of the private sector on public health policies. The United Nation Millennium Declaration emphasizes that the development process depends on the contribution of all organizations [9]. Consequently every organization is encouraged to become more socially responsible.

Many international collaborative programmes are focused on controlling disease-specific problems instead of tackling public health in general [2]. However, it is essential to first provide basic health care and to build local acceptable infrastructures to improve public health in the developing world. The public and private sectors, non governmental organizations and the rest of the actors fighting diseases are thus challenged to integrate efforts for building capacities and ensure sustainable development programmes.

\section{Clinical research and sustainability of the programmes}

The HIV/AIDS pandemic triggered the raise in public and private funds to invest in international research programmes. As a consequence, clinical research has become an essential mean in international cooperation projects and more academic physicians are working in research institutions from resource-limited countries [10]. Besides, one of the prevalent economic theories of growth points to the need of substantially increasing aid to poor countries to allow them to exit from poverty traps [11]. Cooperation between health (academic) institutions of poor and rich countries completely accomplish with this objective, not just realizing investments but also generating capacities and improving medical 
research of diseases that would be, otherwise, ignored. There are many successful examples of collaborative programmes between high and low income countries on the basis of clinical research established in the second half of the $20^{\text {th }}$ century in some African countries such as the Ifakara Health Institute in Tanzania, the Malaria Research and Training Center in Mali, the Kintampo Health Research Centre in Ghana and the Manhiça Health Research Center in Mozambique. Characteristically, training and capacity building of local staff constitute key elements in these collaborative programmes to ensure the challenging and essential long-term sustainability of the projects.

\section{The Gedamaytu pilot project of the Medical University of Vienna}

In this issue Lagler et al. [12] present a new programme of the Medical University of Vienna in Gedamaytu, eastern Ethiopia, a land-extended country with an estimated population, in the year 2007, of roughly 79 millions inhabitants and a gross domestic product per capita of 245 US\$, corresponding approximately to 0.68 US\$ per person per day [13]. The United Nations Development Programme ranked Ethiopia as $171^{\text {st }}$ out of a total 182 countries according to its Human Development Index (HDI) level [14]. Statistics pointed to an improvement of many health indicators over the last twenty years [15]. However, in 2007, the under 5 mortality rate in Ethiopia was of 119 deaths per 1,000 live births and the maternal mortality ratio was estimated to be of 720 maternal deaths per 100,000 live births. In Europe and central Asia the under 5 mortality rate was of 23.4 deaths per 1000 live births that same year and the maternal mortality ratio was 45 per 100,000 live births in 2005 .

The project presented by Lagler et al. aims at establishing an effective development cooperation for sustainable improvement of healthcare. The results from the cross-sectional survey conducted in Gedamaytu show among others, the need to strengthen local capacities at the health post. The success of international cooperation depends on many factors deeply studied by organization sciences [16]. Some specific challenges may potentially characterise the agreement between Vienna and Gedamaytu. Firstly, the geographical context may influence the success of the public health interventions. In fact, like in other low income countries, in Ethiopia the vicious circle poor health-poverty is made worse by armed conflicts and political instability. In addition, most of the population in Gedamaytu is nomadic because of the harsh climatic conditions of the area and because of the current armed conflict between Ethiopia and Somalia.

These specific conditions may make difficult the development of any long-term health and health research programme in the area. Therefore, the AustrianEthiopian cooperative programme will have to adequately plan the activities to be undertaken and create an appropriate incentive structure of the relevant local actors.
As a pilot study, the work of Lagler et al. provides very important and useful information about the health and population's characteristics from Gedamaytu that can be critical to plan further studies or priority health interventions in the region.

The programme of the Medical University of Vienna is the result of the academic social responsibility of an Austrian institution that fits into the international agenda to improve Global Health and has potential for contributing significantly in the development of low income countries. Efforts should also be made in providing capacity building to ensure sustainability of the projects in the future, bearing in mind that all the development cooperation projects need to aim at the final complete independence of the institutions created through the cooperation itself.

\section{Acknowledgements}

The authors would like to thank Dr. José Luis Puerta (Director of "Dendra Médica. Revista de Humanidades", Madrid) for his significant input selecting relevant bibliographic references.

Financial support: Raquel González is supported by a grant from the Spanish Ministry of Health (Contrato post-Formación Sanitaria Especializada "Rio Hortega", Fondo de Investigaciones Sanitarias, Instituto de Salud Carlos III, ref. CM07/0015) and IDIBAPS, Barcelona, Spain. Elisa Sicuri is supported by a grant from the Bill \& Melinda Gates Foundation through the IPTi (Intermittent Preventive Treatment of malaria in infants) Consortium.

Raquel González, Elisa Sicuri

Conflict of Interest

The authors declare that there is no conflict of interest.

\section{References}

1. Beeharry G (2004) Who's afraid of public-private partnerships in global health? Ars Medica 2: 252-261

2. Garret L (2007) The challenge of global health. Foreign Affairs

3. Panosian C, Coates TJ (2006) The new medical "missionaries" - grooming the next generation of global health workers. N Engl J Med 354 (17): 1771-1773

4. Bloom DE, CD, Sevilla J (2001) The effect of health on economic growth: theory and evidence. National Bureau of Economic Research, Cambridge, MA

5. The World Health report 1996 (1997) Fighting disease, fostering development. World Health Forum 18 (1): 1-8

6. EDCTP (2008) The power of sharing science. Corporate Brochure

7. McCoy D, et al (2009) The Bill \& Melinda Gates Foundation's grant-making programme for global health. Lancet 373 (9675): 1645-1653

8. McCoy D, Chand S, Sridhar D (2009) Global health funding: how much, where it comes from and where it goes. Health Policy Plan 24 (6): 407-417

9. United Nations, U (2000) The United Nations Millenium Declaration, General Assembly resolution 55/2 of 8 September 2000

10. Manabe YC, et al (2009) Resurrecting the triple threat: academic social responsibility in the context of global health research. Clin Infect Dis 48 (10): 1420-1422

11. Sachs JD (2006) The end of poverty: economic possibilities for our time. Penguin Books, New York, xviii, 397 p, [16] p. de pl 
12. Lagler H, et al (2010) Global health and social responsibility: a pilot project of the Medical University of Vienna in eastern Ethiopia. Wien Klin Wochenschr 122: 76-80

13. World Bank (2008) World development indicators database, September 2008. 04.12.08

14. United Nations (2008) Statistics of the human development report
15. Paul J (2008) Millenium development goals: world health and population. World Health Popul 10 (2): 3-4

16. Barret S (1999) A theory of full International Cooperation. J Theoretical Politics 11 (4): 519-541

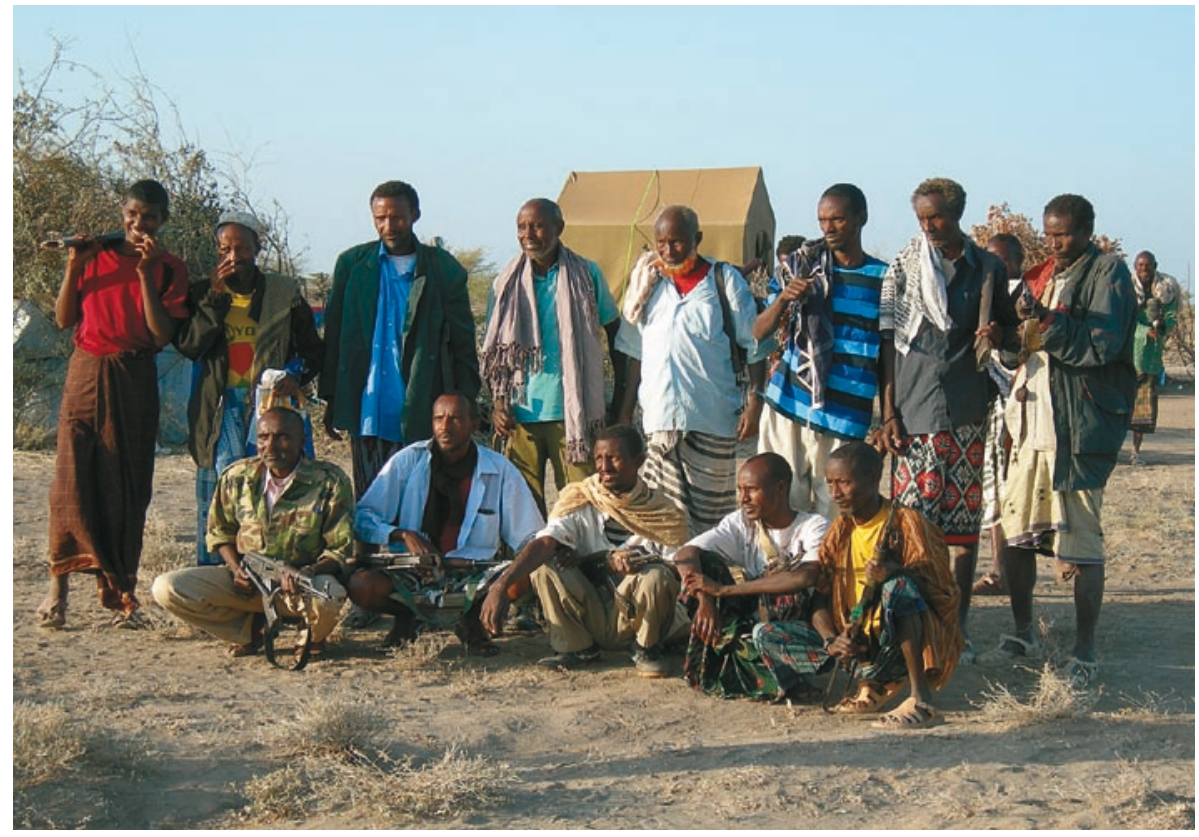

